\title{
High Temperature Modification of SNCR Technology and its Impact on NOx Removal Process
}

\author{
Tomáš Blejchař ${ }^{1, *}$, Jaroslav Konvička ${ }^{2}$, Bernd von der Heide ${ }^{3}$, Rostislav Malý ${ }^{1}$, and Miloš Maier ${ }^{1}$ \\ ${ }^{1}$ ORGREZ, a.s., Hudcova 321/76, 61200 Brno-Medlánky, Czech Republic \\ ${ }^{2}$ VŠB Technical university of Ostrava, 17. listopadu 15/2172, 708 33, Ostrava Poruba, Czech Republic \\ ${ }^{3}$ Mehldau \& Steinfath Umwelttechnik GmbH, Alfredstraße 279, D-45133 Essen, Deutschland
}

\begin{abstract}
SNCR (Selective non-catalytic reduction) Technology is currently being used to reach the emission limit for nitrogen oxides at fossil fuel fired power plant and/or heating plant and optimum temperature for SNCR process is in range $850-1050^{\circ} \mathrm{C}$. Modified SNCR technology is able to reach reduction $60 \%$ of nitrogen oxides at temperature up to $1250^{\circ} \mathrm{C}$. So the technology can also be installed where the flue gas temperature is too high in combustion chamber. Modified SNCR was tested using generally known SNCR chemistry implemented in CFD (Computation fluid dynamics) code. CFD model was focused on detail simulation of reagent injection and influence of flue gas temperature. Than CFD simulation was compared with operating data of boiler where the modified SNCR technology is installed. By comparing the experiment results with the model, the effect on nitrous oxides removal process and temperature of flue gas at the injection region.
\end{abstract}

\section{Introduction}

The retrofitting of large coal fired boilers with $\mathrm{NO}_{\mathrm{X}}$ control systems has been concluded in Western Europe many years ago and in Central Europe has been finishing.

Starting in the nineties a number of Central and Eastern European countries has joined the EU and as a consequence they also had to accept the emission limits which are in force. This means for most of the power plants that the existing boilers either have to be shut down or measures have to reach limits specified by EU regulations like $\mathrm{NO}_{\mathrm{X}}$.

For the SCR technology, which might be the first choice and it was considered as the best available technology (BAT) in the eighties and nineties, many reliable results and experiences are available to estimate the feasibility as well as investment and operating costs with high accuracy. However, beside this fact, that the investment costs for a SCR (Selective catalytic reduction) are about ten times as high as for SNCR system, it is necessary to take into consideration also other disadvantages.

Installation of the catalyst is often very problematic especially when the boiler has a large economiser instead of an air pre-heater so that heat exchangers would have to be re-placed to install the catalyst. Design of SCR layers would generally cause static problems due to the height and weight of the catalyst and additional steel structure. The downtime of the boiler for retrofitting with SCR could cause a considerable loss of profit.
Pressure drop and problematic installation of SCR catalyst could result in higher operating costs for SCR and the investment volume increase to the multiple of the cost of a SCNR system.

The SNCR process has been enhanced for smaller boilers like waste incineration plants in last years, and it is widely considered now as the 'Best Available Technology' (BAT) for this size of boilers. Based on this information an increasing number of owners of power plants are seriously investigating today whether the SNCR process is feasible for their large boilers. Special attention is typically being paid to the overall cost compared to SCR.

\section{Elementary description of the SNCR technology}

The basic principle of NOx reduction by the $\mathrm{NH}_{2}{ }^{-}$radical has been known since the 1970s. A dominant chemical reaction is very simple and is defined by the following chemical formula [1], [2], [3], [4].

$$
\mathrm{NH}_{2}^{-}+\mathrm{NO} \rightarrow \mathrm{N}_{2}+\mathrm{H}_{2} \mathrm{O}
$$

This reaction occurs dominantly without a catalyser in the temperature window between $850-1050^{\circ} \mathrm{C}$. The main problem of SNCR method is a relatively narrow temperature window $\left(850-1050^{\circ} \mathrm{C}\right)$. If the reagent is injected into colder temperature zone in a furnace, nitrogen oxides $\mathrm{NO}_{\mathrm{X}}$ do not react with $\mathrm{NH}_{2}^{-}$radical, because the reaction rate is slow and high concentrations of Ammonia $\mathrm{NH}_{3}$ occur in flue gas. If the reagent is 
injected into warmer temperature zone of the furnace, $\mathrm{NH}_{2}^{-}$reacts with oxygen $\mathrm{O}_{2}$. Therefore, nitrogen oxides are not reduced but they are produced by combustion of ammonia. However the reduction of $\mathrm{NO}_{\mathrm{X}}$ is only 50$65 \%$ at stochiometric ratio ca 2,8 in typical boiler and the SNCR processes achieve reasonable $\mathrm{NO}_{\mathrm{X}}$ reduction only in a narrow range of temperature (extremity 850$1050^{\circ} \mathrm{C}$, optimum $950^{\circ} \mathrm{C}$ ). [1], [4]

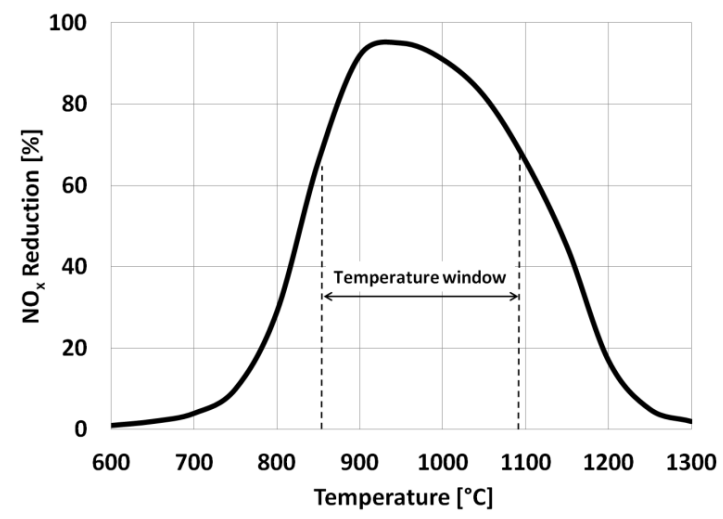

Fig. 1. $\mathrm{NO}_{\mathrm{X}}$ reduction as a function of temperature and illustration of temperature window [1], [4]

\subsection{Elementary chemistry of SNCR process}

Three different commercial processes are usually used at the present time: Thermal DeNOx, NOxOUT and RAPRENOx These methods are based on injection of Ammonia $\mathrm{NH}_{3}$, Urea $\mathrm{CO}\left(\mathrm{NH}_{2}\right)_{2}$ and Cyanuric acid $(\mathrm{HCNO})_{3}$ into combustion chamber of boiler.

The Thermal DeNOx process was originally proposed by Lyon in the USA in 1975, with ammonia as a reduction reagent. This process was developed as a substitution of SCR, which eliminates disadvantage of catalytic reduction such a high cost, poisoning of catalyst, required space, etc. This process involves addition of ammonia $\mathrm{NH}_{3}$ or ammonia water $\mathrm{NH}_{4} \mathrm{OH}$ as a reducing reagent. The DeNOx process can be described by the following chemical net reaction [1], [4]

$$
4 \mathrm{NH}_{3}+4 \mathrm{NO}+\mathrm{O}_{2} \rightarrow 4 \mathrm{~N}_{2}+6 \mathrm{H}_{2} \mathrm{O}
$$

First test of injecting urea solution downstream to the combustion zone to reduce $\mathrm{NO}_{\mathrm{X}}$ in a non-catalytic way was reported in 1977. This process was later patented in USA with a market name NOxOUT. The use of a urea as a reducing reagent is mainly interesting for reason of storage and handling. The NOxOUT process can be described by the following chemical net reaction [1], [4]

$$
2 \mathrm{CO}\left(\mathrm{NH}_{2}\right)_{2}+4 \mathrm{NO}+\mathrm{O}_{2} \rightarrow 4 \mathrm{~N}_{2}+2 \mathrm{CO}_{2}+4 \mathrm{H}_{2} \mathrm{O}
$$

Furthermore, the paper deals only with a method based on the injection of an aqueous solution of urea.

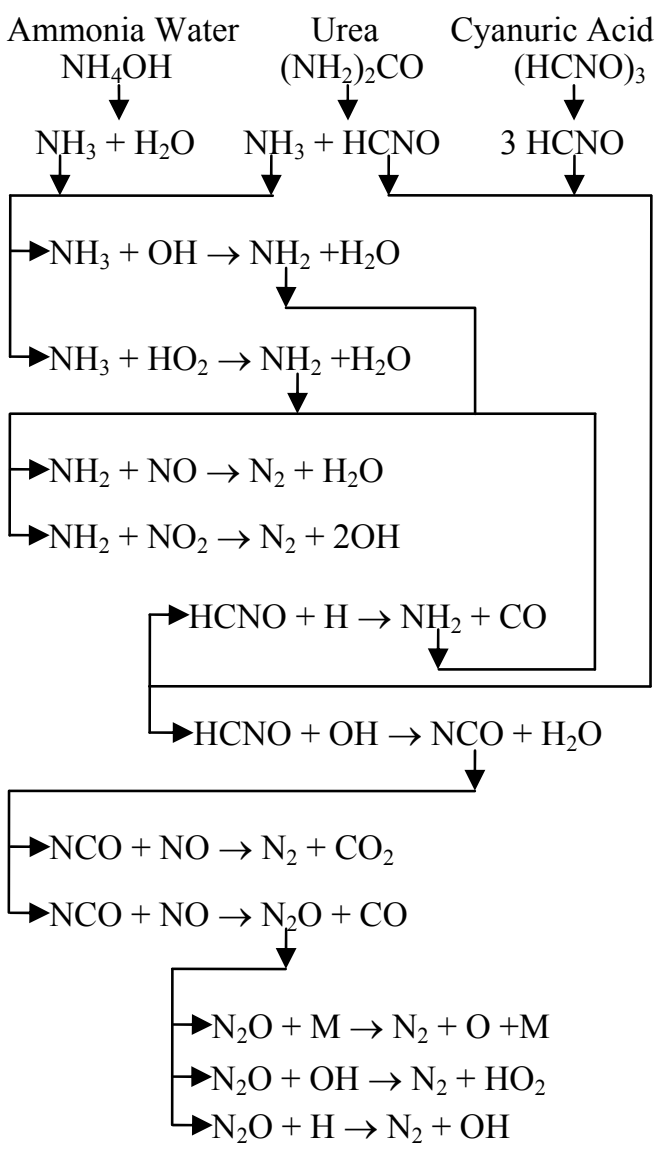

Fig. 2. Simplified chemical mechanism of SNCR method

\subsection{Kinetics data of SNCR process}

Chemical reactions included in CFD are based on the Arrhenius equation (4), which describes the reaction rate [11].

$$
k=A \cdot e^{\frac{-E}{R T}} \cdot T^{\beta}\left[\left(\frac{m o l}{m^{3}}\right)^{1-n} \cdot \frac{K^{-\beta}}{s}\right]
$$

where: $k$ is reaction rate, $A$ is pre-exponential factor, $E$ is activation energy, $R$ is universal gas constant, $T$ is temperature, $\beta$ is temperature exponent, and $n$ is the sum of the number of reaction orders.

The Arrhenius equation describes the rate of reaction only. The chemical mechanism of every reaction must be specified with parent and children materials of reaction and with stoichiometric coefficients [11], [12], [6], [7].

The SNCR model described in this paper is based on seven-step kinetic mechanism of NO defined by Brouwer at al [3] and two-step mechanism for primary breakdown of Urea into $\mathrm{NH}_{3}$ and $\mathrm{HCNO}$ defined by Rota at al. [10]

$$
\begin{gathered}
\left(\mathrm{NH}_{2}\right)_{2} \mathrm{CO} \rightarrow \mathrm{NH}_{3}+\mathrm{HCNO} \\
\left(\mathrm{NH}_{2}\right)_{2} \mathrm{CO}+\mathrm{H}_{2} \mathrm{O} \rightarrow 2 \mathrm{NH}_{3}+\mathrm{CO}_{2} \\
\mathrm{NH}_{3}+\mathrm{NO} \rightarrow \mathrm{N}_{2}+\mathrm{H}_{2} \mathrm{O} \\
\mathrm{NH}_{3}+\mathrm{NO}_{2} \rightarrow \mathrm{N}_{2}+\mathrm{H}_{2} \mathrm{O}
\end{gathered}
$$




$$
\begin{gathered}
\mathrm{NH}_{3}+\mathrm{O}_{2} \rightarrow \mathrm{NO}+\mathrm{H}_{2} \mathrm{O} \\
\mathrm{HCNO}+1 / 4 \mathrm{O}_{2} \rightarrow \mathrm{NCO}+1 / 2 \mathrm{H}_{2} \mathrm{O} \\
\mathrm{NCO}+\mathrm{NO} \rightarrow \mathrm{N}_{2} \mathrm{O}+\mathrm{CO} \\
\mathrm{N}_{2} \mathrm{O} \rightarrow \mathrm{N}_{2}+\mathrm{O}_{2} \\
\mathrm{CO}+1 / 2 \mathrm{O}_{2} \rightarrow \mathrm{CO}_{2}
\end{gathered}
$$

Another modification of SNCR kinetics mechanism can be found in many studies and papers e.g.[8],[9], and [10].

The simplified SNCR reaction mechanism is described by previous reactions. Whereas the reaction mechanism with $\mathrm{NH}_{2}^{-}$radical is complicated that is why the proposed mechanism does not include Ammonia radical $\mathrm{NH}_{2}^{-}$, that means the problematic non-stable transitional material, is not necessary to be specified. The proposed chemical mechanism for SNCR with Urea solution is relatively precise and simple. The complexity and computational intensity of CFD simulation depend on many materials and reactions. The reaction mechanism was proposed with respect to simulation speed and usability.

Table 1. Kinetics parameters of SNCR Model.

\begin{tabular}{|c|c|c|c|c|}
\hline Reaction & $\begin{array}{c}\mathbf{A} \\
{\left[\left(\frac{m o l}{m^{3}}\right)^{1-n} \cdot \frac{K^{-\beta}}{s}\right]}\end{array}$ & $\begin{array}{c}\boldsymbol{\beta} \\
{[1]}\end{array}$ & $\begin{array}{c}\mathbf{E} \\
{\left[\frac{J}{m o l}\right]}\end{array}$ & $\begin{array}{c}\mathbf{n} \\
{[1]}\end{array}$ \\
\hline Eqv. (5) & $1,27 \mathrm{E}+04$ & 0 & 65048 & $\begin{array}{c}1 \\
{\left[\left(\mathrm{NH}_{2}\right)_{2} \mathrm{CO}\right]^{1}}\end{array}$ \\
\hline Eqv. (6) & $6,13 \mathrm{E}+04$ & 0 & 87819 & $\begin{array}{c}2 \\
{\left[\left(\mathrm{NH}_{2}\right)_{2} \mathrm{CO}\right]^{1}} \\
{\left[\mathrm{H}_{2} \mathrm{O}\right]^{1}}\end{array}$ \\
\hline Eqv. (7) & $4,20 \mathrm{E}+02$ & 5,3 & 315937 & $\begin{array}{c}2 \\
{\left[\mathrm{NH}_{3}\right]^{1}} \\
{\left[\mathrm{NO}^{1}\right.}\end{array}$ \\
\hline Eqv. (8) & $4,20 \mathrm{E}+02$ & 5,3 & 349937 & $\begin{array}{c}2 \\
{\left[\mathrm{NH}_{3}\right]^{1}} \\
{\left[\mathrm{NO}_{2}\right]^{1}}\end{array}$ \\
\hline Eqv. (9) & $3,50 \mathrm{E}-03$. & 7,65 & 544487 & $\begin{array}{c}2 \\
{\left[\mathrm{NH}_{3}\right]^{1}} \\
{\left[\mathrm{O}_{2}\right]^{1}}\end{array}$ \\
\hline Eqv. (10) & $6,24 \mathrm{E}+09$ & 0,85 & 284637 & $\begin{array}{c}1,25 \\
{\left[\mathrm{HNCO}^{1}\right.} \\
{\left[\mathrm{O}_{2}\right]^{1}}\end{array}$ \\
\hline Eqv. (11) & $1,00 \mathrm{E}+07$ & 0 & -1632 & $\begin{array}{c}2 \\
{\left[\mathrm{NCO}^{1}\right.} \\
{\left[\mathrm{NO}^{1}\right.}\end{array}$ \\
\hline Eqv. (12) & $6,90 \mathrm{E}+12$ & $-2,5$ & 151075 & $\begin{array}{c}1 \\
{\left[\mathrm{~N}_{2} \mathrm{O}\right]^{1}}\end{array}$ \\
\hline & $1,26 \mathrm{E}+06$ & 0 & 167742 & $\begin{array}{c}1,75 \\
{[\mathrm{CO}]^{1}} \\
{\left[\mathrm{O}_{2}\right]^{0,25}} \\
{\left[\mathrm{H}_{2} \mathrm{O}\right]^{0,5}}\end{array}$ \\
\hline
\end{tabular}

\subsection{Influence of CO concentration on SNCR process}

The presence of $\mathrm{CO}$, where reagent is injected, affects kinetics of $\mathrm{NO}_{\mathrm{X}}$ reduction with urea. Effect of $\mathrm{CO}$ oxidation leads to production of $\mathrm{H}, \mathrm{O}$, and $\mathrm{OH}$ due to reactions (14)-(16).

$$
\begin{gathered}
\mathrm{CO}+\mathrm{OH} \leftrightarrow \mathrm{CO}_{2}+\mathrm{H} \\
\mathrm{H}+\mathrm{O}_{2} \leftrightarrow \mathrm{O}+\mathrm{OH} \\
\mathrm{O}+\mathrm{H}_{2} \mathrm{O} \leftrightarrow \mathrm{OH}+\mathrm{OH}
\end{gathered}
$$

The influence of CO on the SNCR process indicating that the presence of $\mathrm{CO}$ shifts the selectivity by increasing the rate of $\mathrm{NH}_{2}^{-}$formation and the rate of $\mathrm{NH}_{3}$ oxidation to NO. Higher $\mathrm{CO}$ level shifts the optimal temperature for $\mathrm{NO}$ reduction to lower temperatures due to enhanced chemical rates in presence of $\mathrm{CO}$. The shift in selectivity is accomplished by two mechanisms:

- Increasing local temperature

- Increasing net production of $\mathrm{OH}$ radical.

The firs effect is due to exothermicity of the main CO burnout reaction (14), while the second effects is due to chain branching that results from the $\mathrm{H}$ produced in this reaction. The contribution of $\mathrm{CO}$ oxidation to the local temperature is accounted for in the model. Empirical adjustment to the rates is used to account for the effect of $\mathrm{CO}$ without including details radical chemistry. The empirical adjustment is applied in the form of shift in effective temperature to account for the radical chemistry effects of $\mathrm{CO}$ as follows and the rate of reactions $(7),(8),(9),(10)$ is modified as [3]

$$
k=A \cdot e^{\frac{-E}{R\left(T+S_{C O}\right)}} \cdot\left(T+S_{C O}\right)^{\beta}
$$

$\mathrm{S}_{\mathrm{CO}}$ is the shift in the temperature required to achieve the same NO reduction and reagent decomposition compared to the case without $\mathrm{CO}$ [3].

$$
\mathrm{S}_{\mathrm{CO}}=17,5 \cdot \ln \left(\mathrm{X}_{\mathrm{CO}}\right)+173
$$

where $\mathrm{X}_{\mathrm{CO}}$ is volume fraction of $\mathrm{CO}$. Application of modified rate of reaction is not possible to set in CFD code ANSYS CFX. Analysis of equation (15) shown that this equation can be simplified as follows and term $\mathrm{X}_{\mathrm{CO}}{ }^{\gamma}$ describes $\mathrm{CO}$ shift in simplified form.

$$
k=A \cdot X_{C O}{ }^{\chi} \cdot e^{\frac{-E}{R T}} \cdot T^{\beta}
$$

Table 2. Kinetics parameters of SNCR Model with CO shift.

\begin{tabular}{|c|c|c|c|c|c|}
\hline Reaction & $\begin{array}{c}\mathbf{A} \\
{\left[\left(\frac{m o l}{m^{3}}\right)^{1-n} \cdot \frac{K^{-\beta}}{s}\right]}\end{array}$ & $\begin{array}{c}\boldsymbol{\beta} \\
{[1]}\end{array}$ & $\begin{array}{c}\gamma \\
{[1]}\end{array}$ & $\begin{array}{c}\mathbf{E} \\
{\left[\frac{J}{m o l}\right]}\end{array}$ & $\begin{array}{c}\mathbf{n} \\
{[1]}\end{array}$ \\
\hline Eqv. (7) & $8,63 \mathrm{E}+04$ & 5,27 & 0,58 & 311822 & $\begin{array}{c}2 ; \\
{\left[\mathrm{NH}_{3}\right]^{1}} \\
{\left[\mathrm{NO}^{1}\right.}\end{array}$ \\
\hline Eqv. (8) & $1,39 \mathrm{E}+05$ & 5,27 & 0,63 & 345403 & $\begin{array}{c}2 ; \\
{\left[\mathrm{NH}_{3}\right]^{1}} \\
{\left[\mathrm{NO}_{2}\right]^{1}}\end{array}$ \\
\hline
\end{tabular}




\begin{tabular}{|c|c|c|c|c|c|}
\hline Eqv. (9) & $2,63 \mathrm{E}+01$ & 7,61 & 0,97 & 537456 & $\begin{array}{c}2 ; \\
{\left[\mathrm{NH}_{3}\right]^{1}} \\
{\left[\mathrm{O}_{2}\right]^{1}}\end{array}$ \\
\hline Eqv. (10) & $3,88 \mathrm{E}+11$ & 0,84 & 0,46 & 281090 & $\begin{array}{c}1,25 \\
{[\mathrm{HNCO}]^{1}} \\
{\left[\mathrm{O}_{2}\right]^{1}}\end{array}$ \\
\hline
\end{tabular}

Previous equation was used to analysis of kinetics data of reactions (7), (8), (9), (10) calculated by equation (15) and (16). The influence of CO on the SNCR process can be described by modifying the kinetic parameters of the equations (7), (8), (9), (10).

\subsection{Influence of $\mathrm{O}_{2}$ concentration}

The influence of oxygen concentration in flue gas in the SNCR process was presented in several studies. Higher concentration of oxygen shifts the temperature window towards lower temperatures. The higher concentration of oxygen did not involve reduction of $\mathrm{NO}_{\mathrm{X}}$.

\subsection{Influence of $\mathrm{H}_{2} \mathrm{O}$ concentration}

Presence of $\mathrm{H}_{2} \mathrm{O}$ in flue gas also affects the efficiency of $\mathrm{NO}_{\mathrm{X}}$ reduction. Concentration of $\mathrm{H}_{2} \mathrm{O}$ in reacting zone effects due to radical $O$. This radical inhibits the formation of $\mathrm{NH}_{2}{ }^{-}$. The process of inhibition is described by following reactions [1]:

$$
\begin{gathered}
\mathrm{O}+\mathrm{H}_{2} \mathrm{O} \leftrightarrow \mathrm{OH}+\mathrm{OH} \\
\mathrm{NH}_{2}+\mathrm{OH} \leftrightarrow \mathrm{NH}_{3}+\mathrm{O}
\end{gathered}
$$

Higher concentration of water in flue gas shifts the temperature window to higher temperatures. But this effect is not cross-validated.

\subsection{Influence of $\mathrm{H}_{2}$ concentration}

Addition of hydrogen shifts the temperature to lower values. Process of dissociation and/or oxidation of hydrogen produce radicals $\mathrm{OH}, \mathrm{H}$ and $\mathrm{O}$. These radicals influence the concentration of $\mathrm{NH}_{2}^{-}$.due to the $\mathrm{NH}_{3} \rightarrow \mathrm{NH}_{2} \cdot$ conversion, see following equations

$$
\begin{aligned}
\mathrm{NH}_{3}+\mathrm{OH} & \leftrightarrow \mathrm{NH}_{2}+\mathrm{H}_{2} \mathrm{O} \\
\mathrm{NH}_{3}+\mathrm{O} & \leftrightarrow \mathrm{NH}_{2}+\mathrm{OH} \\
\mathrm{NH}_{3}+\mathrm{H} & \leftrightarrow \mathrm{NH}_{2}+\mathrm{H}_{2}
\end{aligned}
$$

\section{High temperature modification of SNCR - Selective cooling of the flue gas}

SNCR technology can operate in a narrow range of temperature (extremity $850-1050^{\circ} \mathrm{C}$, optimum $950^{\circ} \mathrm{C}$ ). This temperature window occurs usually upstream heat exchangers like super heater, over heater etc. Sometimes the temperature window reaches up to domain where the heat exchangers are located. If the flue gas reaches heat exchangers than the temperature of flue gas fall very fast. It means if the reagent (urea) is injected just upstream heat exchangers than the reagent reaches cold walls of exchanger very quick and the process of $\mathrm{NO}_{\mathrm{X}}$ reduction is stopped due to low temperature of flue gas. Another necessary condition is residence time of reagent at temperature window which cannot be met in the case of injection of reagent just upstream heat exchangers. Sometimes SNCR technology cannot be designed for the above-mentioned reasons because temperature of flue gas is too high in combustion chamber and upstream heat exchangers respectively.

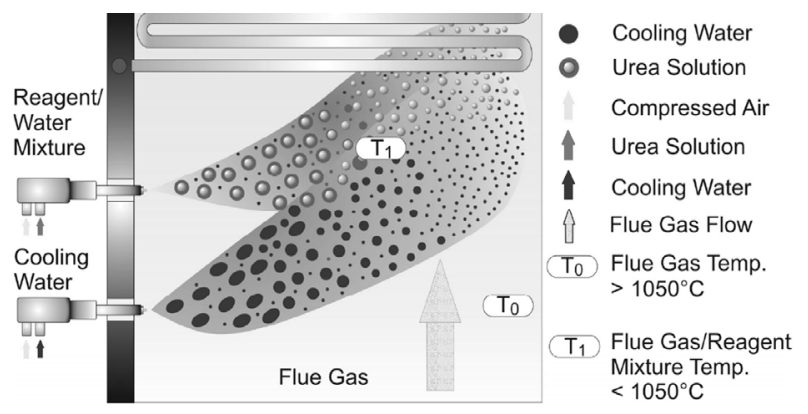

Fig. 3. Basic principle of selective cooling of flue gas

As has been said, the presence of $\mathrm{H}_{2} \mathrm{O}$, where reagent is injected, affects kinetics of $\mathrm{NO}_{\mathrm{X}}$ reduction and higher concentration of $\mathrm{H}_{2} \mathrm{O}$ in flue gas shifts the temperature window to higher temperatures. This leads to the idea that if additional water can be transported to the injection region, SNCR technology will be able to operate at higher temperatures.

In cases when the flue gas temperatures are too hot, as is mostly the case at load peaks and/or in limited areas, cooling of the flue gas might be a viable alternative. This simply could be accomplished by increasing the quantity of process water. Since the changing of the fluid flow in the injectors would change the spraying pattern as well, a better solution is to install additional injectors for cooling water close to the reagent injectors.

With this concept, cooling water can be switched on or off for each injector independently when needed depending on the flue gas temperature in this location, while the distribution of the reagent would not be affected.

\section{CFD model of selective cooling of the flue gas}

The problem of the jet penetration and mixing in turbulent cross flow is relevant in many industrial applications, and it has been studied by several researchers. The characteristic mixing time is not exactly the time required for molecular mixing of primary cross flow with the lateral jet stream. However, the mixing time can be an important tool when compared with the reaction time scales, in order to predict the operating conditions where the mixing can play an important role. 
The SNCR technology is relatively a simple technological unit, but it includes some important parts which affect dominantly the efficiency of $\mathrm{NO}_{\mathrm{x}}$ reduction. One of important parts is a nozzle. Three types of nozzles are generally used at present. The following nozzles are used: 1) cone spraying nozzle, 2) plane spraying nozzle, 3) cone spraying nozzle with an angle of $45^{\circ}$. The main parameters of the nozzle and injection lance are affected by the sprayed reagent and the depth of penetration of flue gas by reagent respectively. It is not possible to measure the spraying process in situ, because the nozzles are situated in the combustion chamber. Due to the insufficient information about the process of spraying and cooling of the flue gas, it was decided to analyse the flow in the nozzle in detail. The spraying process is theoretically demonstrated by mixing of two perpendicular flows of fluids. The main flow is flue gas and the second flow is the air with droplets of urea solution.

The penetration of flue gas is ca $2 \mathrm{~m}$. This is a low value according to the dimension of the combustion furnace. The $\mathrm{NO}_{\mathrm{X}}$ molecules are reduced near the wall of combustion chamber and the core of flue gas flow is not affected by reagent. Therefore, there is a significant problem with balanced penetration of flue gas and this is the main reason of low efficiency of SNCR reaching ca $65 \%$ at high stoichiometric ratio ca 2.8 .

Table 3. Penetration of flue gas by reagent.

\begin{tabular}{|c|c|}
\hline Nozzle type & $\begin{array}{c}\text { Penetration } \\
\text { [m] }\end{array}$ \\
\hline Cone & ca $1,2-2,4$ \\
\hline Plane & ca $0,6-2,1$ \\
\hline Cone $45^{\circ}$ & ca $0,9-2,4$ \\
\hline
\end{tabular}

The process of selective cooling of flue gas was simulated on the base of real design of SNCR technology. Simulation domain and boundary condition was focused on detail of couple of injection lances (regent and cooling water) with cone nozzle.

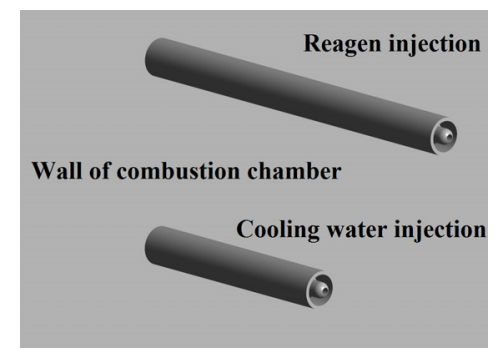

Fig. 4. Detail of simulation domain

So the domain was basically a large duct with two injection lances, which was perpendicular to main flow of flue gas in duct. Grid was strictly built form hexahedral elements and total number of elements was approximately 850000 .

The basic equation set, which describes both regimes of flow, represents the application of the conservation laws. The law of mass, momentum and energy conservation are used for numerical modelling of flow [12]. The law of momentum conservation represents the Navier-Stokes equation [12]. The law of mass conservation represents the continuity equation [12], and the law of energy equation represents the energy equation [12]. The CFD code ANSYS CFX was used for simulations. Turbulent flow is stochastic, but it is statistic stable. Arbitrary physical quantity can be decompiled on sum of average value and fluctuation value $u=\bar{u}+u^{\prime}$. Commonly used turbulent models are based on description of local turbulent intensity by length and velocity scale. Flow regime was analysed by means of Reynolds number.

$$
\operatorname{Re}=\frac{\rho \cdot v \cdot D}{\eta} \approx 100000
$$

Where: $v$ is velocity $[\mathrm{m} / \mathrm{s}], D$ is characteristic dimension [m], $\rho$ is density $\left[\mathrm{kg} / \mathrm{m}^{3}\right]$ and $\eta$ is dynamic viscosity $\left[\mathrm{Pa}^{*} \mathrm{~s}\right]$ of the fluid.

As is evident, this is a turbulent flow and the jet flow produces shear stress. That is why Shear Stress Transport k- $\omega$ turbulence model is used for CFD simulation [12]. The turbulent viscosity is specified by two transport equations. These equations solve turbulent kinetic energy and vorticity $\omega[12]$. The production of turbulence by expansion is included in the simulation too

As already mentioned, the CFD simulation was focused on effect of water injection upstream injection area of reagent at higher temperature of flue gas than optimal. The practical experience with the selective cooling system already exists and this system is installed and operated. But the process of cooling of flue gas is not fully understood yet.

Boundary condition was specified on the base of the process data that was recorded during the commissioning and optimizing of the SNCR technology with selective cooling system. Test of selective cooling was realised at maximum load of the boiler if the temperature of the flue gas is maximum. Effect of cooling water was evaluated on the base of time record of boiler process data.

The first step of the test was stabilisation of maximum load of the boiler and then was started SNCR technology in automatic mode. After the suppression of the effects of unsteady running (PID regulator reach the set value of $\mathrm{NO}_{\mathrm{X}}$ ) were installed suction pyrometers 1,3 $\mathrm{m}$ upstream couple of cooling and injection lances. The suction pyrometers were used do measure of flue gas temperature. Flue gas sucked up through the pyrometer were analysed by FTIR [8] equipment and the analysis was mainly focused on concentration of $\mathrm{O}_{2}, \mathrm{CO}$ and $\mathrm{NO}_{\mathrm{x}}$.

Once the boiler was stabilised and all important values were approximately constant so technology was blocked. PID regulator was deactivated so all valves and other regulation equipment were "frozen" in current status. Next SNCR technology was ready for selective cooling test.

The test was very simple and consisted of a manual closing of the cooling water supply. This test thus 
showed the response of the SNCR system to the presence of cooling water in the injection area and 100 mm upstream respectively.

In the picture we can see that if the cooling water was not in the injection area than the concentration of NOx increased from ca 185 to ca $275 \mathrm{mg} / \mathrm{m}_{\mathrm{N}}^{3}$ in the stack of power plant.

As already mentioned, the CFD model and its boundary conditions were defined on the base of cooling water test. Computation domain represented approximately one sixth of the real combustion chamber. CFD simulation the simulation was calculated for two basic conditions, 1) the cooling nozzle switched on and 2) the cooling nozzle switched off. This corresponded to the selective cooling test.

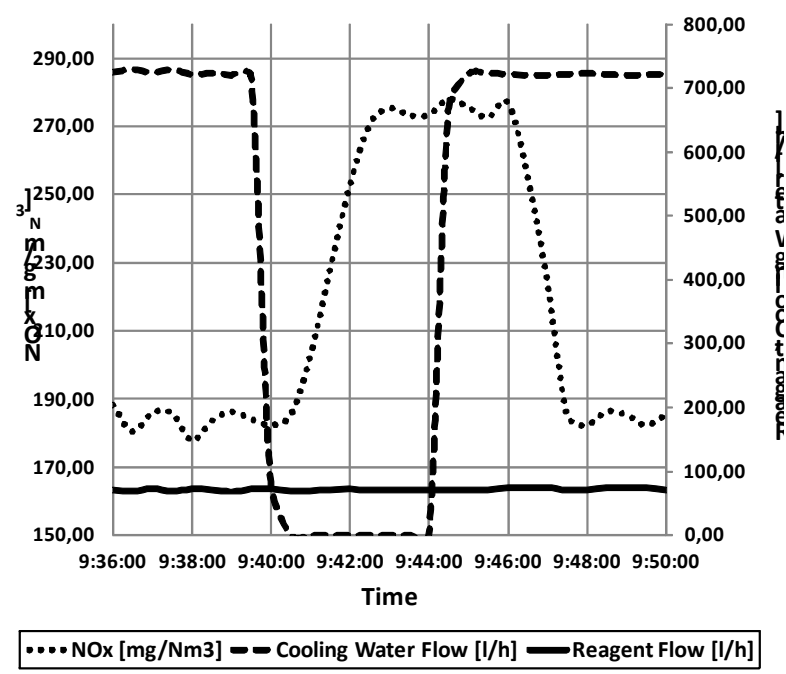

Fig. 5. Results of cooling system test

\section{Results of CFD simulation}

Results of CFD simulation were compared with time record data of selective cooling test. The most important is the effect of cooling water on $\mathrm{NO}_{\mathrm{X}}$ reduction that is why the effect of cooling water was evaluated by reduction of NOx concentration, which means reduced amount of reduced $\mathrm{NO}_{\mathrm{X}}$ and $\mathrm{NO}$ respectively, see next table.

Table 4. Penetration of flue gas by reagent.

\begin{tabular}{|c|c|c|}
\hline $\begin{array}{c}\text { Reduction of } \mathbf{N O}_{\mathbf{x}} \\
{[\mathbf{\%}]}\end{array}$ & Test & CFD \\
\hline Cooling lance ON & 43 & 22 \\
\hline Cooling lance OFF & 16 & 6 \\
\hline $\begin{array}{c}\text { Effect of Cooling } \\
\text { water }\end{array}$ & +27 & +16 \\
\hline
\end{tabular}

As it is evident from the previous table CFD model is not reach the same reduction. Compared to the test, the reduction is approximately $50 \%$ lower. This means, that the model is pessimistic and understates the effect of cooling water in injection area.
Next the effect of cooling water was investigated in injection area. Following figures shown the concentration field of NO in plane parallel to flue gas flow and the plane is located in the centre of lances. Cooling water in injection area creates cold cover where the temperature is lower than temperature of surrounding gas which is too high. Inside this area the temperature is ideal for reduction of $\mathrm{NO}(7)$ and $\mathrm{NO}_{2}(8)$.

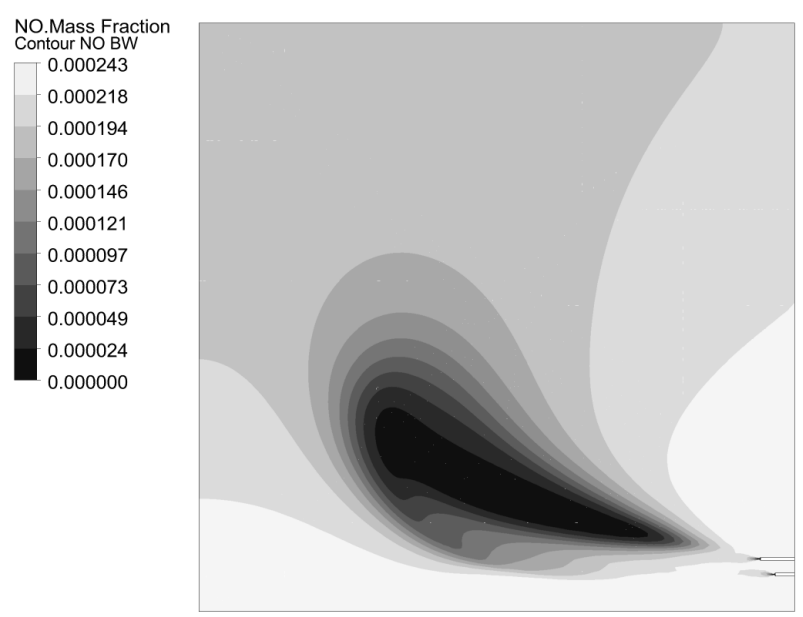

Fig. 6. Concentration field of NO, horizontal plane parallel to flue gas flow, cooling lance $\mathrm{ON}$

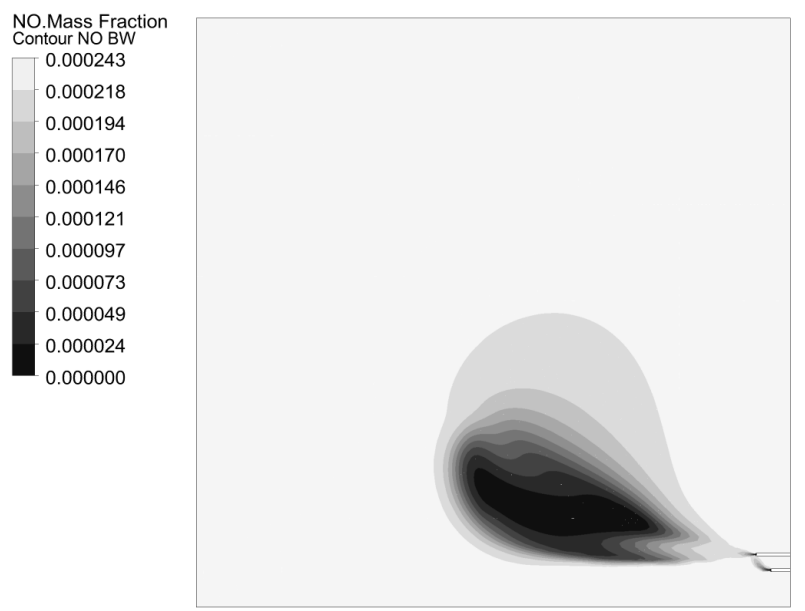

Fig. 7. Concentration field of NO, horizontal plane parallel to flue gas flow, cooling lance OFF

When the cooling water is not in injection area than temperature is too high. $\mathrm{NO}$ and $\mathrm{NO}_{2}$ are reduced but only in area where reagent is evaporated. Temperature exceeds the upper limit of the temperature window outside and reagent produces NO (9).

\section{Conclusion}

The paper is focused on the simulation of high temperature modification of SNCR technology which is based on injection of cooling water upstream injection area of reagent. Chemical reactions used to describing of SNCR process are able to predict quite accurately the reduction of NO, but chemistry of SNCR process is strongly simplified due to practical usability and 
limitation of number of chemical equations included in the CFD model. Described CFD model of SNCR process can be used for prediction of the efficiency of SNCR technology, but the model in not able to describe complexity of the phenomena.

Effect of cooling water injection upstream injection area of reagent was analysed on the base of real test. Recorded data of the test was used to definition of CFD model of couple of injection and cooling lance. Whereas the proposed SNCR model does not include detail chemistry of $\mathrm{OH}$ radical, than the CFD model is not able to describe full effect of cooling water in injection area. This is evident from a comparison of the test results and CFD model. Effect of cooling water is reduced to local cooling due to evaporation of water.

The project will continue and future goal will be modification of kinetics of SNCR process, which describes effect which fully describes the effect of water on the rate of chemical reactions and shift of temperature window to higher temperatures.

\section{Acknowledgment}

The paper was prepared within the Project of MPO ČR TIP No. FI-IM4/193 "Research and Development of Nozzles for SNCR Technology in Power Engineering Focused on Elimination of Negative Effects of SNCR

\section{References}

1. A. Kohl, R. Nielsen, Gas Purification, Fifth Edition, Gulf Publishing Company, Houston, Texas, (1997), ISBN 0-88415-220-0

2. X. Hou, H. Zhang, M. Pilawska, J. Lu, G. Yue, The formation of $\mathrm{N}_{2} \mathrm{O}$ during the reduction of $\mathrm{NO}$ by $\mathrm{NH}_{3}$, Fuel, p. 3271-3277, 87 (2008)

3. J. Brouwer, M. P. Heap, D. W. Pershing, and P. J. Smith, A Model for Prediction of Selective NonCatalytic Reduction of Nitrogen Oxides by Ammonia, Urea, and Cyanuric Acid with Mixing Limitations in the Presence of CO. 26th Symposium (Int'l) on Combustion. The Combustion Institute. 1996.

4. B. von der Heide, Ist das SNCR-Verfahren noch Stand der Technik, Thomé-Kosmiensky, Michael Beckmann (Hrsg.): Energie aus Abfall, TK Verlag Karl Thomé-Kozmiensky, 275 - 293, 4, ISBN 9783-935317-32-0

5. Ch. R. Choi, Ch. N. Kim, Numerical investigation on the flow, combustion and $\mathrm{NO}_{\mathrm{X}}$ emission characteristics in a 500 MWe tangentially fired pulverized-coal boiler, Fuel, 1720-1731, 88 (2009)

6. Y. Lu, I. Hippinen, A. Jahkola Control of NOx and $\mathrm{N} 2 \mathrm{O}$ in pressurized fluidized-bed combustion Fuel, 317-322, 74 (1995)

7. R. Rota, E. F. Zanoelo, Influence of oxygenated additives on the NOxOUT process efficiency Fuel, 765-770, 82 (2003)

8. D. R. Tree, A. W Clark Advanced reburning measurements of temperature and species in a pulverized coal flame Fuel, 1687-1695, 79 (2000)
9. J. A. Miller, G. T, Bowman, Mechanism and modeling of nitrogen chemistry, Combustion, Progress in Energy and Combustion Science , 287338,15 (1989)

10. R. Rota, D. Antos, E. F. Zanoelo, M. Morbidelli, Experimental and Modeling Analysis of the NOxOUT Process, Chemical Engineering Science, 27-38, 57 (2002)

11. M. Čarnogurská, T. Brestovič, M. Příhoda, Modelling of Nitrogen Oxides Formation Applying Dimensional Analysis, Chemical and Process Engineering, 175-184, 32 (2011), ISSN 0208-6425

12. Ansys, Inc., ANSYS CFX-Solver Theory Guide, (2016) 